\title{
The Role of Autologous Platelet Concentrates in Alveolar Socket Preservation: A Systematic Review
}

\author{
Marco Annunziata ${ }^{a} \quad$ Luigi Guida $^{a}$ Livia Nastria Angelantonio Piccirillo $^{a} \quad$ Linda Sommese $^{b}$ \\ Claudio Napolic,d \\ a Multidisciplinary Department of Medical-Surgical and Dental Specialties, University of Campania 'Luigi Vanvitelli', Naples, Italy; \\ bU.O.C. Division of Clinical Immunology, Immunohematology, Transfusion Medicine and Transplant Immunology, \\ Regional Reference Laboratory of Transplant Immunology, Azienda Ospedaliera Universitaria, Department of Experimental Medicine, \\ University of Campania 'Luigi Vanvitelli', Naples, Italy; \\ c U.O.C. Division of Clinical Immunology, Immunohematology, Transfusion Medicine and Transplant Immunology, \\ Regional Reference Laboratory of Transplant Immunology, Department of Internal and Specialty Medicine, \\ Azienda Ospedaliera Universitaria, University of Campania 'Luigi Vanvitelli', Naples, Italy; \\ dDepartment of Medical, Surgical, Neurological, Metabolic and Geriatric Sciences, University of Campania 'Luigi Vanvitelli', Naples, Italy
}

\section{Keywords}

Platelet-rich plasma - Tooth extraction .

Alveolar bone loss

\section{Summary}

Prevention of alveolar bone resorption after tooth extraction may be useful for implant rehabilitation of the edentulous site minimizing the future need for bone augmentation procedures. A number of studies have investigated the efficacy of autologous platelet concentrates for the preservation of the alveolar bone volume after tooth extraction. Although encouraging results have been published, the available data are still controversial. The aim of the present systematic review was to assess the effect of platelet concentrates on alveolar socket preservation after tooth extraction. A literature search was carried out up to September 2017 for prospective controlled trials in which a test group using exclusively a platelet concentrate was compared with a control group in which extraction sockets were left to heal spontaneously. Seven controlled clinical trials published between 2010 and 2016 were included. A total of 320 extractions (170 tests and 150 controls) in 190 patients was considered. A great heterogeneity was found in terms of study design, methodological aspects, and outcome evaluation. For this reason, a quantitative anal-

Marco Annunziata and Luigi Guida contributed equally to the work and share the first authorship. ysis followed by meta-analysis was not possible, and only a descriptive analysis on the role of platelet concentrates in alveolar socket preservation was carried out. There is growing evidence that platelet concentrates may be advantageously used in postextraction sites, mainly to improve soft tissue healing and to reduce postoperative symptoms. Data about their potential in preserving the alveolar bone volume are still scarce and controversial, although recently encouraging results have been presented using more reliable and accurate evaluation technologies, such as the computed tomography. Further, well-designed and methodologically standardized investigations are strongly demanded to reach a higher level of evidence on this topic.

(c) 2018 S. Karger GmbH, Freiburg

\section{Introduction}

Tooth extraction does not purely imply the loss of a functional dental unit. It also causes a huge local alteration of hard and soft tissue architecture, with possible relevant implications for the prosthetic rehabilitation of the future edentulous site including the installation of a dental implant in a functionally and aesthetically reliable position [1].

The postextraction dimensional alteration of the alveolar process (or alveolar ridge) has been widely studied in humans by means of clinical, cast model and radiographic examinations [2-8].

\section{KARGER}

(c) 2018 S. Karger GmbH, Freiburg
Dr. Linda Sommese 
Table 1. Systematic search strategy

\begin{tabular}{|c|c|}
\hline Search string & $\begin{array}{l}\text { 'PRP' OR 'platelet rich plasma' OR 'PRF' OR 'platelet rich fibrin' OR 'PRGF' OR 'plasma rich in } \\
\text { growth factors' AND 'extraction socket' OR 'tooth extraction' OR 'alveolar socket' OR 'socket } \\
\text { preservation' OR ' socket' }\end{array}$ \\
\hline Language & No restrictions \\
\hline Electronic databases & MEDLINE/PubMed, Cochrane Central Register of Controlled Trials (CENTRAL), ClinicalTrials.gov \\
\hline Inclusion criteria & $\begin{array}{l}\text { Study design: interventional studies either randomized controlled clinical trials (RCT) and non- } \\
\text { randomized controlled clinical trials (CCT) } \\
\text { Population: partially edentulous patients } \\
\text { No restriction on age or number of patients } \\
\text { Healthy individuals (no systemic diseases, no medications affecting platelet and bone functions) } \\
\text { Intervention: alveolar socket preservation using an autologous plasma concentrate } \\
\text { Comparison: no biomaterial in the control group; only clot in the socket } \\
\text { Outcome: qualitative and /or quantitative changes of soft and hard tissues. } \\
\text { Follow-up duration: at least } 2 \text { months for hard tissue healing, } 3 \text { weeks for soft tissue healing }\end{array}$ \\
\hline Exclusion criteria & $\begin{array}{l}\text { Studies involving extraction of impacted third molars } \\
\text { Studies involving platelet concentrates used in combination with bone grafts/biomaterials or } \\
\text { immediate implant placement } \\
\text { All other types of study design, such as observational studies, technical reports, conference abstracts, } \\
\text { pre-clinical studies and reviews }\end{array}$ \\
\hline
\end{tabular}

The greatest amount of alveolar alteration occurs in the horizontal dimension, mainly on the buccal aspect. The buccal bone, indeed, is frequently thin and is mainly composed of 'bundle bone' which is a tooth-dependent structure totally and invariably disappearing after tooth loss. Due to tooth loss and to the resorption of the alveolar walls, soft tissues collapse into the alveolus contributing to the reduction of the original alveolar dimensions. Three months after tooth extraction up to $50 \%$ reduction of the original alveolar width may occur, although a great interindividual variability exists, and remodeling phenomena may continue up to 1 year postextraction [7].

'Socket preservation' is a surgical procedure aimed to preserve the alveolar ridge after extraction with the aim to eliminate or minimize the need for future augmentation surgical procedures for implant-prosthetic rehabilitations. The main part of the proposed socket preservation techniques includes the use of bone or bone substitute grafts in conjunction with or without membranes. Another approach for socket preservation is mainly focused on the enhancement of the alveolar healing process by the use of biological mediators. Platelets have many functions beyond the hemostatic one. Activated platelets released growth factors and cytokines such as fibrinogen, basic fibroblast growth factor, fibronectin, angiopoietin-2, insulin-like growth factor-I, platelet-derived growth factor, transforming growth factor- $\beta 1$ (TGF- $\beta 1$ ), and vascular endothelial growth factor which play an essential role in soft and hard tissue healing $[9,10]$.

Platelet-rich plasma (PRP) was the first platelet concentrate used in dentistry after the breakthrough study of Marx et al. [11]. Different types of platelet concentrates were developed from the original PRP by changing the centrifugation and preparation protocol. Until now, three types of platelet concentrates have been proposed for socket preservation: PRP, PRGF (plasma rich in growth factors) and PRF (platelet-rich fibrin). However, data about their potential in favoring alveolar healing and its dimensional preservation are still not univocal. The aim of the present study was to review systematically the available scientific literature to evaluate the efficacy of autologous platelet concentrates for postextraction alveolar socket preservation.

\section{Material and Methods}

The search strategy used in this systematic review was based on the PRISMA (Preferred Reporting Items for Systematic reviews and Meta-Analyses) guidelines (www.prisma-statement.org) [12]. Clinical questions were formulated according to the PICO framework for evidence-based practice [13].

The focused question was: 'What is the effect of platelet concentrates on alveolar socket preservation compared with spontaneous alveolar socket healing?'.

A literature search was carried out on September 2017 by two independent and calibrated reviewers in the database of the National Library of Medicine MEDLINE/PubMed, in the Cochrane Central Register of Controlled Trials, and in the ClinicalTrials.gov website. The authors adopted an ad hoc created search string: ('PRP' OR 'platelet rich plasma' OR 'PRF' OR 'platelet rich fibrin' OR 'PRGF' OR 'plasma rich in growth factors') AND ('extraction socket' OR 'tooth extraction' OR 'alveolar socket' OR 'socket preservation' OR 'socket'). No language restriction was applied.

All randomized controlled trials and controlled clinical trials were included assessing the efficacy of platelet concentrates for healing and regeneration of hard and soft tissues in patients undergoing tooth extraction. Subjects considered eligible for the study were free of systemic diseases and free of medications affecting platelet and bone functions. No restriction on age or number of patients was considered. Studies were included only if a test group using platelet concentrates was compared with a control group in which platelet concentrates were not used. Any type of platelet concentrate was considered, but not if used in combination with other biomaterials. Studies were included if the follow-up duration was at least 2 months for hard tissue healing and 3 weeks for soft tissue healing. Preclinical studies, case reports, case series, retrospective studies, letters to the editor, technical reports, narrative reviews as well as studies that included the extraction of impacted third molars or immediate placement of implants were excluded. Moreover, conference abstracts were not considered.

The main features of the bibliographic search are reported in table 1. All full text studies were carefully read and analyzed for the eligibility criteria (inclusion/exclusion). 


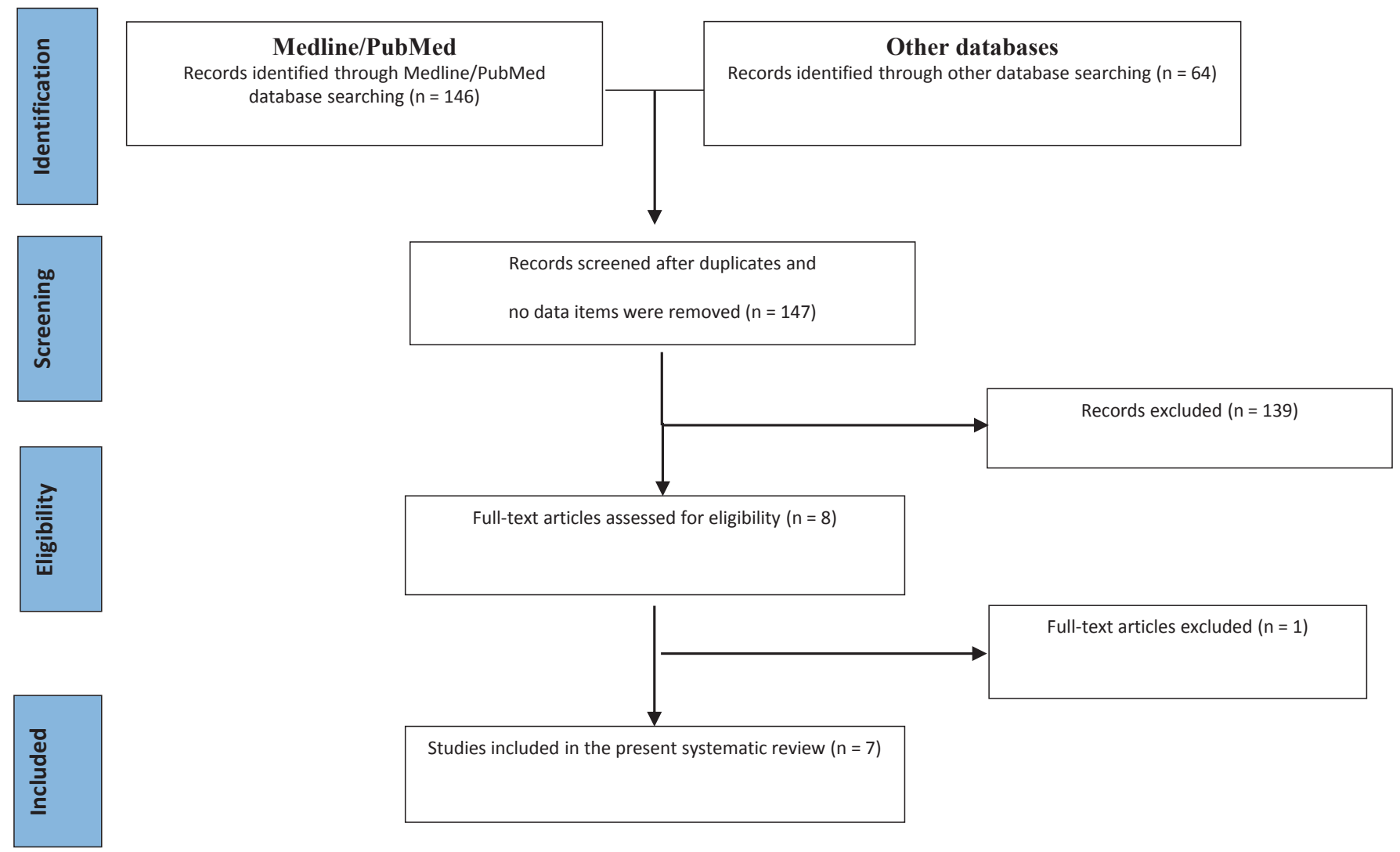

Fig. 1. Flow diagram (PRISMA format) of the screening and selection process.

The heterogeneity of the primary results of the studies included in this review was evaluated according to the following factors: study design, study population, tooth type, reason for extraction, extraction method and intervention, outcomes, evaluation method, evaluation time, results, and conclusions. The methodological quality of each study was assessed according to the criteria suggested by Van der Weijden et al. [14] with some modifications. The potential risk of bias was calculated based on the quality criteria met by each study. After analysis of the selected studies, data on dimensional (vertical and horizontal) changes of the soft and hard tissues as well as bone fill values were collected. Mean/medians and their standard deviations/errors were recorded when available. Other data, such as postoperative complications, healing and analysis of newly formed tissues, were also collected. However, due to the heterogeneity of data among studies, a quantitative analysis followed by meta-analysis was not possible, and only a descriptive analysis was performed.

\section{Results}

146 items in MEDLINE/PubMed and 64 in other sources (50 in the Cochrane Central Register of Controlled Trials and 14 in the ClinicalTrials.gov website) were found after the initial search. Only three of six includible trials registered in the ClinicalTrials.gov website were completed, but the results were not uploaded by authors, so none of them was included in the present review. After duplicates and items with no data available were removed, 147 records remained. After screening of titles and abstracts for inclusion/exclusion criteria, 139 studies were excluded and 8 studies remained. One study was excluded after full-text evaluation [15] because of the adjunctive use of a bone graft in the experimental groups. At the end of the process, 7 prospective studies published between 2010 and 2016 were included in this systematic review (fig. 1). All excluded studies with the explanation of exclusion reason are listed in appendix 1 (available at http://content.karger.com/ ProdukteDB/produkte.asp?doi=488061).

The examination of the included studies revealed high heterogeneity in terms of aim, design and protocol, results obtained, and conclusion reached. The main characteristics of selected studies are described in tables 2-4 as well as in supplemental table 1 (available at $h t t p: / / c o n t e n t . k a r g e r . c o m / P r o d u k t e D B / p r o d u k t e . a s p ? d o i=488061)$. In particular, study design, characteristics of the study population, tooth type, and reason for extraction are reported in table 2. The surgical protocol for tooth extraction in terms of surgical devices and techniques used, flap management and type of wound healing are reported in table 3. The different methods used in the selected studies to prepare platelet concentrates as reported in table 4 . The results of the methodological quality assessment of the included studies are presented in table 5 .

The results (including outcome, method of evaluation, and significance of the effect) and the conclusions reached by all included articles are shown in supplemental table 1 (available at $h t t p: / / c o n-$ tent.karger.com/ProdukteDB/produkte.asp?doi=488061). Soft tissue healing was evaluated in five of the seven studies included [15-19]. A qualitative assessment of hard tissue healing was carried out in five of the seven included studies (supplemental table 1, available at http://content.karger.com/ProdukteDB/produkte.asp?doi=488061) $[15,16,18,20,21]$. 


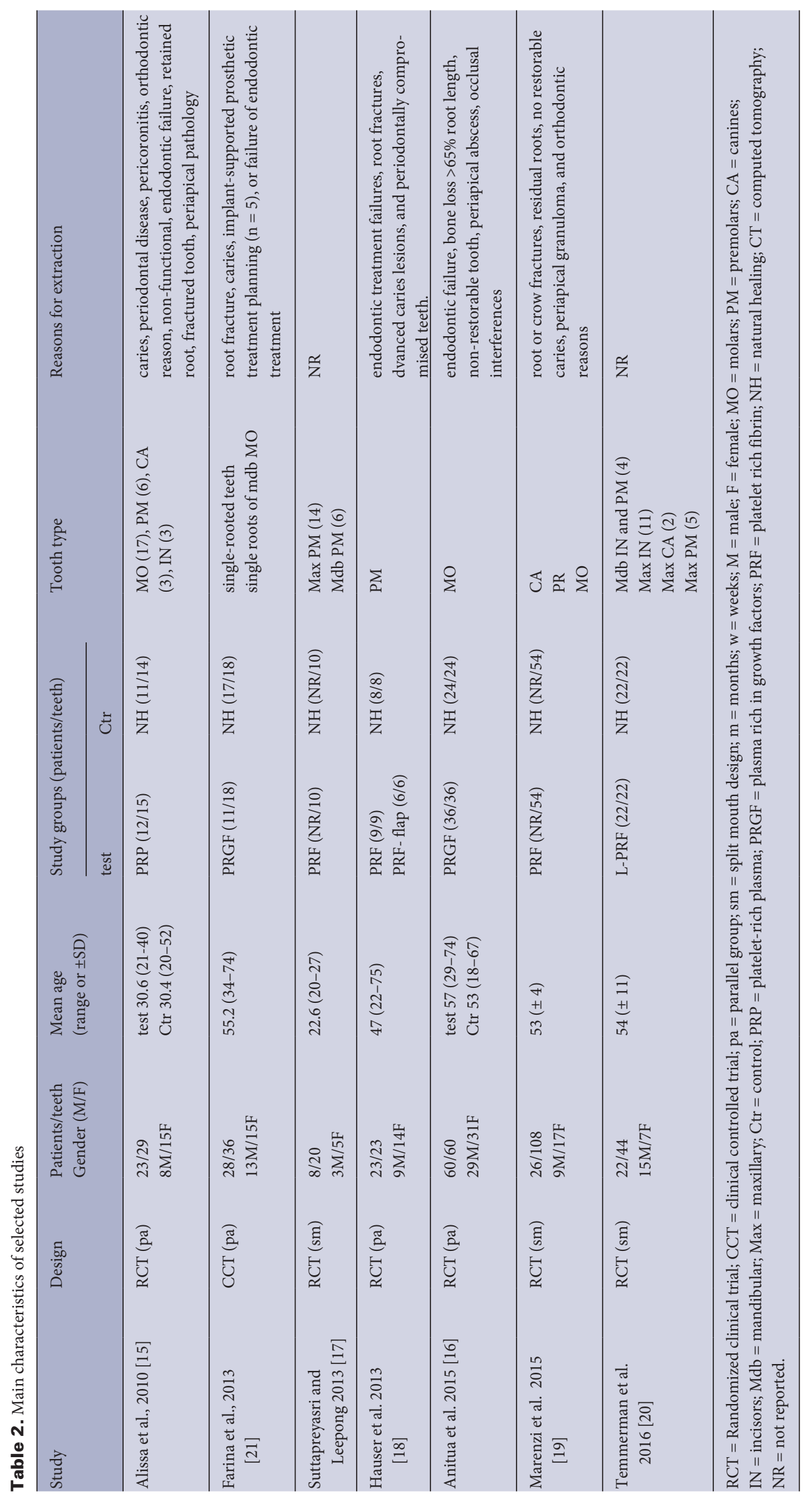


Table 3. Main characteristics of selected studies: extraction operative protocol

\begin{tabular}{llll}
\hline Study & Extraction techniques/devices & Flap/flapless & Type of healing \\
\hline Alissa et al., 2010 [15] & $\begin{array}{l}\text { minimally traumatic/elevators, } \\
\text { forceps and alveolar cleaning }\end{array}$ & flap & I intention \\
\hline Farina et al., 2013 [21] & $\begin{array}{l}\text { minimally traumatic/ elevators, luxators, } \\
\text { forceps, rotating burs and scalpels to } \\
\text { separate roots }\end{array}$ & flapless & II intention \\
\hline Suttapreyasri and Leepong 2013 [17] & minimally traumatic/elevators, forceps & flapless & II intention \\
\hline Hauser et al. 2013 [18] & $\begin{array}{l}\text { minimally traumatic/scalpel for the } \\
\text { syndesmotomy, elevators, forceps and } \\
\text { alveolar cleaning }\end{array}$ & $\begin{array}{l}\text { flap and flapless } \\
\text { group }\end{array}$ & II intention \\
\hline Anitua et al. 2015 [16] & $\begin{array}{l}\text { minimally traumatic/ manual periotome, } \\
\text { forceps and surgical bur to separate roots }\end{array}$ & flapless & II intention \\
\hline Marenzi et al. 2015 [19] & $\begin{array}{l}\text { minimally traumatic/NR } \\
\text { minimally traumatic/ periotomes and } \\
\text { alveolar cleaning }\end{array}$ & flapless & II intention \\
\hline Temmerman et al. 2016 [20] & flapless & II intention \\
\hline
\end{tabular}

Table 4. Main characteristics of selected studies: methods for platelet concentrate preparation

\begin{tabular}{|c|c|c|c|c|c|}
\hline Authors & $\begin{array}{l}\text { Type of platelet concentrate and } \\
\text { centrifugation system }\end{array}$ & $\begin{array}{l}\text { Volume of blood } \\
\text { drawn, } \mathrm{ml}\end{array}$ & $\begin{array}{l}\text { Anti-coagulant } \\
\text { solution }\end{array}$ & $\begin{array}{l}\text { Centrifugation } \\
\text { parameters, } \\
\text { no., speed, time }\end{array}$ & Activator \\
\hline Alissa et al., 2010 [15] & $\begin{array}{l}\text { PRP } \\
\text { Platelet Concentrate System PCCS II } \\
\text { (3i Implants Innovations, Palm Beach } \\
\text { Gardens, FL, USA) }\end{array}$ & 27 & citrate dextrose & $\begin{array}{l}1 \times \\
3,200 \mathrm{rpm} \\
12 \mathrm{~min}\end{array}$ & $\begin{array}{l}\text { autologous } \\
\text { trombin }\end{array}$ \\
\hline Farina et al., 2013 [21] & $\begin{array}{l}\text { PRGF } \\
\text { PRGF System IV (BTI Biotechnology } \\
\text { Institute, Vitoria-Gasteiz, Spain) }\end{array}$ & 20 & trisodium citrate & $\begin{array}{l}1 \times \\
580 \mathrm{~g} \\
8 \mathrm{~min}\end{array}$ & $\begin{array}{l}\text { calcium } \\
\text { chloride }\end{array}$ \\
\hline $\begin{array}{l}\text { Suttapreyasri and Leepong } \\
\quad 2013 \text { [17] }\end{array}$ & $\begin{array}{l}\text { PRF } \\
\text { EBA } 20 \text { (Andreas Hettich GmbH and } \\
\text { Co., KG, Tuttlingen, Germany) }\end{array}$ & 10 & none & $\begin{array}{l}1 \times \\
3000 \mathrm{rpm} \\
10 \mathrm{~min}\end{array}$ & none \\
\hline Hauser et al. 2013 [18] & $\begin{array}{l}\text { PRF } \\
\text { NR }\end{array}$ & 8 & none & $\begin{array}{l}1 \times \\
2,700 \mathrm{rpm} \\
12 \mathrm{~min}\end{array}$ & none \\
\hline Anitua et al. 2015 [16] & $\begin{array}{l}\text { PRGF } \\
\text { PRGF System (BTI Biotechnology } \\
\text { Institute S.L, Vitoria, Spain) }\end{array}$ & 10 & $\begin{array}{l}3.8 \% \text { sodium } \\
\text { citrate }\end{array}$ & $\begin{array}{l}1 \times \\
580 \mathrm{~g} \\
8 \mathrm{~min}\end{array}$ & $\begin{array}{l}10 \% \text { calcium } \\
\text { chloride }\end{array}$ \\
\hline Marenzi et al. 2015 [19] & $\begin{array}{l}\text { PRF } \\
\text { Intra-Spin L-PRF kit ( Intra-Lock, } \\
\text { Boca-Raton, FL, USA) }\end{array}$ & 9 & none & $\begin{array}{l}1 \times \\
2,700 \mathrm{rpm} \\
12 \mathrm{~min}\end{array}$ & none \\
\hline $\begin{array}{l}\text { Temmerman et al. } 2016 \\
\text { [20] }\end{array}$ & $\begin{array}{l}\text { L-PRF } \\
\text { Intra-Spin L-PRF kit (Intra-Lock, } \\
\text { Boca-Raton, FL, USA) }\end{array}$ & 10 & none & $\begin{array}{l}1 \times \\
2,700 \mathrm{rpm} \\
12 \mathrm{~min}\end{array}$ & none \\
\hline
\end{tabular}

Only three studies investigated the alterations of the alveolar ridge after postextraction application of platelet derivatives as reported in supplemental table 1 (available at $h t t p: / /$ content.karger. com/ProdukteDB/produkte.asp?doi=488061) [17, 18, 20]. Four studies investigated the postoperative symptoms and quality of life (e.g. pain, complications) following to the surgical procedure as re-

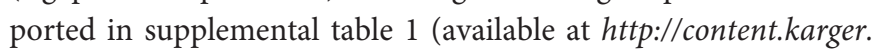
com/ProdukteDB/produkte.asp?doi=488061) $[15,16,19,20]$. 


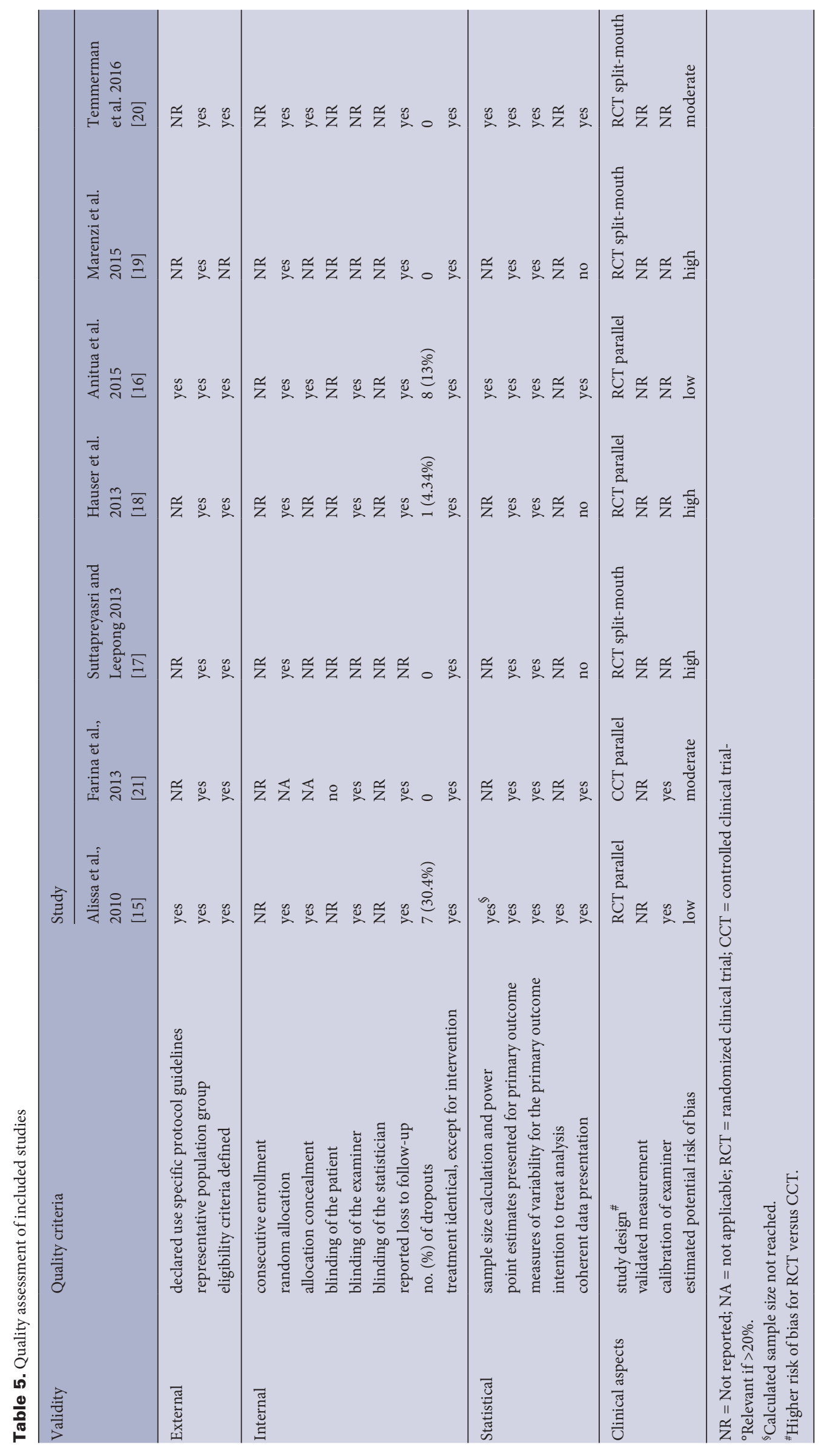




\section{Data Meta-Analysis}

Meta-analysis of data among the studies was not possible because of the great heterogeneity in design and in data presentation even if similar outcomes were measured (such as radiographic alveolar height, bone fill, and pain symptoms).

\section{Discussion}

The application of platelet derivatives has become commonplace in several fields of regenerative medicine such as dentistry, maxillofacial and orthopedic surgery as well as ophthalmology although their therapeutic effects have to be confirmed yet [22,23].

In the dental field, the possibility of using a simple procedure and totally autologous growth factors for the management of postextraction alveolar modifications is particularly fascinating in view of future dental implant therapy. However, at the moment, there is no consensus on the real benefits of platelet concentrates in this indication, with only few papers being published on this topic showing heterogeneous and in some cases low methodological quality as pointed out in recent reviews [24-27].

In order to limit this heterogeneity and to allow a study comparison, we decided, to adopt restrictive inclusion/exclusion criteria in our search strategy.

We included only prospective controlled clinical trials comparing the use of different types of platelet concentrates in a postextraction alveolar socket compared with a control site left to heal spontaneously, excluding all other types of studies. In contrast to other reviews [24-26], we decided to exclude studies on impacted third molars, due to the osteotomy of the socket walls that frequently is made in such extractions, and studies in which platelet concentrates were used in combination with bone grafts, trying to investigate only the platelet concentrate influence on the healing process. Unlike in other reviews $[24,26]$, only studies involving healthy patients as well as patients not assuming any medication with possible effects on platelets or on bone metabolism were included, in order to limit the confounding variables and facilitate the interpretation of results.

The qualitative assessment performed on the 7 included studies revealed that only two of them $[15,16]$ showed a low potential risk of bias, and this aspect contributed to reduce further the availability of reliable literature data on this topic. Besides purely methodological aspects, also other inconsistencies and limitations were evident after a careful reading of some of these papers (e.g. discrepancies between data reported in the text and those presented in the respective tables or graphics in terms of values and/or significance, see also adjunctive notes in supplemental table 1 (available at http://content.karger.com/ProdukteDB/produkte.asp?doi=488061) for more details [17-20].

Among the 7 studies included, substantial heterogeneities were found in our analysis at the end of the screening phase for the characteristics of the patient population, tooth location and type, surgical protocol, method for obtaining the platelet concentrate, outcome variables, success criteria, and follow-up time. These differ- ences made data analysis difficult and precluded the comparison of the results among the different studies.

Tooth location and type may influence alveolar morphologic changes after tooth extraction. First, ridge alterations are very different if there are or not teeth adjacent to the extraction site and if single or multiple adjacent extractions are made. Furthermore, according to Pietrokovski and Massler [4], the amount of alveolar resorption (in the buccal-lingual dimension) was significantly greater in the molar region than in other regions of both jaws, as measured on cast models before and after tooth extraction.

Also the cause of extraction may be important and affect the rate of postextraction alveolar resorption. For instance, the dimension of the residual alveolus is significantly reduced in case of periodontally compromised teeth, or bony walls may be damaged for an occurred trauma or root fracture, resulting in a different pattern of postextraction alveolar resorption compared with teeth having intact alveolar bony walls.

Although all aspects regarding tooth extraction are of paramount importance in studying the alveolar healing and preservation process, only general details about the cause of extraction as well as the devices and techniques used were usually provided in the included studies.

Two studies $[17,20]$ did not report the cause of extraction at all. Only in one study [16] the authors considered a threshold in terms of residual bone among the inclusion/exclusion criteria. In all other studies, both periodontally compromised teeth and fractured roots were included, but adequate details about the baseline characteristics or the possible intraoperative damage of the alveolar walls were not provided.

The extraction procedure was always described as minimally traumatic by using periotomes, elevators and forceps, and separating roots when needed with the aim to maintain the buccal plate and the interradicular bony septa.

Different methods have been proposed to prepare platelet concentrates. Among the included studies, one used PRP, two PRGF and four PRF (table 4); however, it is difficult to clearly identify a technique more efficient than another. Actually, there are a lot of variables that may play a role in platelet viability and activity within tissues: cell separator used, centrifugation method (single- or double-step), amount of blood collected preoperatively, baseline platelet concentration in the collected blood, amount of platelet concentrate obtained, final increase of platelet concentration, type of blood anticoagulant and platelet activator used $[9,22]$. As an example, the technology for obtaining PRGF is designed to produce a leucocyte-free preparation with the specific aim of reducing the content of pro-inflammatory cytokines. Other preparations like PRP or PRF contain a medium to high concentration of leukocytes. In the case of PRP, centrifugation speed and time and the type of anti-clotting and activation agents used may affect the quality and quantity of cells. These factors are less critical in the preparation of PRF, because natural clotting occurs after centrifugation, and the addition of anti-clotting agents, thrombin, and calcium hydrochloride to change the biochemical properties of blood is not necessary. This is the reason why PRF is the plasma concentrate which is easi- 
est to prepare [28]. In terms of concentration of growth factors, recent studies have compared the growth factor release from different platelet concentrate families. However, definitive data cannot be provided [9]. In a work of 2012, growth factor release was much more intense in the L-PRF than in PRGF, but it is not possible to claim that one technique would be better than the other since both families of products can have a potential positive impact on tissue healing [29]. In a recent study, the authors aimed to compare growth factor release over time from PRP, PRF, and a modernized protocol for PRF such as advanced-PRF (A-PRF) [30]. The results indicate that the advantage of PRP is the release of significantly higher amounts of proteins at earlier time points whereas PRF displayed a continual and steady release of growth factors over a 10 day period. Then, the new formulation of PRF (A-PRF) resulted in significantly higher in total quantities of growth factors when compared to traditional PRF [30]. The platelet content of the different types of platelet concentrates may influence their effect on tissues [31]. One study found the limit of $1,000,000 \mathrm{PLT} / \mu \mathrm{l}$ as the optimal platelet concentration for the enhancement of tissue repair/regeneration. However, data about this aspect are poor, and very few attempts have been made to standardize the platelet number and to refer it to the obtained clinical results [9].

Regarding the time point adopted for outcome measurements, a 3-month period for hard tissue and 3-week period for soft tissue evaluation, would seem to be reasonable. Indeed, it has been shown that the maximum changes in alveolar healing after tooth extraction happens in the first 3 months, whereas just few weeks are enough to obtain a complete wound closure or at least a complete re-epithelization even if a second intention soft tissue healing occurs [7].

The reported effect of platelet concentrates on bone healing appears to be heterogeneous and in some cases controversial. However, some words, must be spent about the different evaluation methods for bone changes in order to correctly interpret literature data. The qualitative changes of bone tissue have been evaluated by periapical radiographs, histomorphometry, nanoindentation test, or micro-computed tomography. In this sense, a general trend showing no (or a very slight) difference in terms of qualitative features between naturally -healed and platelet concentrate-treated alveolar sockets has been reported $[15,16,18,21]$. The vertical changes of the alveolar socket have been evaluated by bi-dimensional techniques (periapical radiographs). The two studies $[17,18]$ evaluating the vertical bone resorption using the same platelet preparation (PRF) and a similar evaluation method (measurement of mesial and distal bone peaks by periapical radiographs), came to opposite conclusions. One [17] failed to find a difference between test and control group, although the qualitative assessment of this study showed a high risk of bias, whereas the other one [18] found a significant alveolar vertical reduction only for the control group, although evident limitations (small sample size, large data variability) for this study exist.

The horizontal changes in the buccal-lingual dimension or the bone filling rate of the postextraction sockets have been evaluated by cone beam computed tomography in two studies $[16,20]$ which reported a significantly lower alveolar resorption and a signifi- cantly higher bone filling for test groups. In our opinion, computed tomographic exams, carried out immediately after tooth extraction and 3 months later, should be preferred to estimating in a repeatable and reliable way the dimensional changes of the alveolar bone.

The findings from our systematic review on the effect of plasma concentrates on postextraction healing are in line with those reported by others [24-27]. As in the previous reviews [24-27], the heterogeneity of the available primary studies did not allow to perform a quantitative analysis of the main clinical outcomes. These reviews reported that platelet concentrates may be beneficial in reducing postoperative pain, swelling, trismus, and inflammation, thereby improving quality of life and comfort in the early period after extraction, although the actual effect on decreasing pain is still not quantifiable $[24,26,27]$. They also highlighted that there is a beneficial effect of platelet concentrates on inducing and accelerating soft tissue healing after tooth extraction [25, 27]. With regard to the effect on hard tissue, these reviews did show only limited evidence for or no effect on bone healing [24, 25, 27]. Only Del Fabbro et al. [26], after performing a meta-analysis, came to the conclusion that the use of platelet concentrates can be advantageous for some relevant clinical and radiographic outcomes, such as soft tissue and bone healing after a dental extraction procedure. However, a comparison with our systematic review is difficult due to the higher number of studies included by Del Fabbro et al. [26] and the more restrictive inclusion criteria adopted in our search strategy. In conclusion, the present systematic review provides some evidence that the use of autologous platelet concentrates after tooth extraction may be beneficial in terms of accelerated soft tissue healing and reduced postoperative symptoms, whilst data about hard tissue healing are still controversial. Encouraging results also on hard tissues have been presented by most recent studies in which more reliable and accurate evaluation technologies such as cone beam computed tomography were used. Due to the current scarcity of comparative data among the different types of platelet preparations used for socket preservation, no recommendation on this aspect can be made. The absence of accepted standards for the production of platelet concentrates significantly limits the consistency of the available data with regard to their biological effects. Furthermore, detailed information about protocols for the preparation of platelet concentrates are rarely provided. Further studies specifically focused on the correlation between platelet count and growth factor concentration of these preparations and their biological effects would be of great help in understanding the heterogeneous set of clinical outcomes found until now. A better standardization of experimental design and methods should be addressed by researchers in order to provide a solid base for the comprehension of the real clinical effect of autologous platelet concentrates on alveolar socket preservation after tooth extraction. In particular, future studies should be performed keeping in mind the following precautions: selection of a homogeneous set of tooth elements in terms of location, type, cause of extraction, adoption of minimally traumatic extraction procedures, and measurement of the baseline alveolar bone levels (preferably by computed tomography of the buccal-lingual dimension) to precisely monitor postextraction changes. 


\section{Disclosure Statement}

The authors declare that they have no conflict of interest in the subject mat-

ter of the manuscript and did not receive any financial support.

\section{References}

1 Araújo MG, Silva CO, Misawa M, Sukekava F: Alveolar socket healing: what can we learn? Periodontol 2000 2015;68:122-134.

2 Atwood DA: Postextraction changes in the adult mandible as illustrate by microradiographs of midsagittal section and serial cephalometric roentgenograms. J Prosthet Dent 1963;13:810-824.

3 Johnson K: A study of the dimensional changes occurring in the maxilla after tooth extraction. Part I - Normal healing. Aust Dent J 1963;8:428-433.

4 Pietrokovski J, Massler M: Alveolar ridge resorption following tooth extraction. J Prosthet Dent 1967;17: 21-27.

5 Johnson K: A study of the dimensional changes occurring in the maxilla following tooth extraction. Aust Dent J 1969; 14:241-244.

6 Bergman B, Carlsson GE: Clinical long-term study of complete denture wearers. Prosthet Dent 1985;53:5661.

7 Schropp L, Wenzel A, Kostopoulos L, Karring T: Bone healing and soft tissue contour changes following single-tooth extraction: a clinical and radiographic 12month prospective study. Int J Periodontics Restorative Dent 2003;23:313-323.

8 Trombelli L, Farina R, Marzola A, Bozzi L, Liljenberg $\mathrm{B}$, Lindhe J: Modeling and remodeling of human extraction sockets. J Clin Periodontol 2008;35:630-639.

$\checkmark 9$ De Pascale MR, Sommese L, Casamassimi A, Napoli C: Platelet derivatives in regenerative medicine: an update. Transfus Med Rev 2015;29:52-56.

10 Pignalosa O, Martusciello D, De Pascale MR, Sommese L, Nicoletti GF, Itro A, Cavalca F, Tartaro G, Napoli C: Platelet gel in a non-regenerating cryosurgery-induced skin wound in an old patient: a case report. Med Princ Pract 2016;25:388-390.

11 Marx RE, Carlson ER, Eichstaedt RM, Schimmele SR, Strauss JE, Georgeff KR: Platelet-rich plasma: growth factor enhancement for bone grafts. Oral Surg Oral Med Oral Pathol Oral Radiol Endod 1998;85:638-646.

12 Moher D, Liberati A, Tetzlaff J, Altman DG; Prisma Group: Preferred reporting items for systematic reviews and meta-analyses: the PRISMA statement. Int J Surg 2010;8:336-341.

13 Schardt C, Adams MB, Owens T, Keitz S, Fontelo P. Utilization of the PICO framework to improve searching PubMed for clinical questions. BMC Med Inform Decis Mak 2007;15:7-16.
Van der Weijden F, Dell'acqua F, Slot DE: Alveolar bone dimensional changes of post-extraction sockets in humans: a systematic review. J Clin Periodontol 2009;36:1048-1058.

15 Alissa R, Esposito M, Horner K, Oliver R: The influence of platelet-rich plasma on the healing of extraction sockets: an explorative randomised clinical trial. Eur J Oral Implantol 2010;3:121-134.

16 Anitua E, Murias-Freijo A, Alkhraisat MH, Orive G: Clinical, radiographical, and histological outcomes of plasma rich in growth factors in extraction socket: a randomized controlled clinical trial. Clin Oral Investig 2015;19:589-600.

17 Suttapreyasri S, Leepong N: Influence of platelet-rich fibrin on alveolar ridge preservation. J Craniofac Surg 2013;24:1088-1094.

18 Hauser F, Gaydarov N, Badoud I, Vazquez L, Bernard JP, Ammann P: Clinical and histological evaluation of postextraction platelet-rich fibrin socket filling: a prospective randomized controlled study. Implant Dent 2013;22:295-303.

19 Marenzi G, Riccitiello F, Tia M, Di Lauro A, Sammartino G: Influence of leukocyte- and platelet-rich fibrin (L-PRF) in the healing of simple postextraction sockets: a split-mouth study. Biomed Res Int 2015;2015:369273.

20 Temmerman A, Vandessel J, Castro A, Jacobs R, Teughels W, Pinto N, Quirynen M: The use of leucocyte and platelet-rich fibrin in socket management and ridge preservation: a split-mouth, randomized, controlled clinical trial. J Clin Periodontol 2016;43:990-999.

21 Farina R, Bressan E, Taut A, Cucchi A, Trombelli L: Plasma rich in growth factors in human extraction sockets: a radiographic and histomorphometric study on early bone deposition. Clin Oral Implants Res 2013; 24:1360-1368.

22 Sequeria JP, Johri S: Platelet rich plasma: clinical applications in dentistry. Sch J Dent Sci 2015;2:355-362.

23 Albanese A, Licata ME, Polizzi B, Campisi G: Plateletrich plasma (PRP) in dental and oral surgery: from the wound healing to bone regeneration. Immun Ageing 2013;10:23.

24 Del Fabbro M, Bortolin M, Taschieri S: Is autologous platelet concentrate beneficial for post-extraction socket healing? A systematic review. Int J Oral Maxillofac Surg 2011;40:891-900.

25 Del Fabbro M, Corbella S, Taschieri S, Francetti L, Weinstein R: Autologous platelet concentrate for postextraction socket healing: a systematic review. Eur J Oral Implantol 2014 Winter;7:333-44.
26 Del Fabbro M, Bucchi C, Lolato A, Corbella S, Testor $\mathrm{T}$, Taschieri S: Healing of postextraction sockets preserved with autologous platelet concentrates. A systematic review and meta-analysis. J Oral Maxillofac Surg 2017 Aug;75:1601-1615.

27 Moraschini V, Barboza ES: Effect of autologous platelet concentrates for alveolar socket preservation: a systematic review. Int J Oral Maxillofac Surg 2015;44: 632-641.

28 Dohan Ehrenfest DM, Rasmusson L, Albrektsson T: Classification of platelet concentrates: from pure platelet-rich plasma (P-PRP) to leucocyte- and platelet-rich fibrin (L-PRF). Trends Biotechnol 2009;27:158-167.

29 Dohan Ehrenfest DM, Bielecki T, Jimbo R, Barbé G, Del Corso M, Inchingolo F, Sammartino G: Do the fibrin architecture and leukocyte content influence the growth factor release of platelet concentrates? An evidencebased answer comparing a pure platelet-rich plasma (P-PRP) gel and a leukocyte- and platelet-rich fibrin (L-PRF). Curr Pharm Biotechnol 2012;13:1145-1152.

30 Kobayashi E, Flückiger L, Fujioka-Kobayashi M, Sawada K, Sculean A, Schaller B, Miron RJ: Comparative release of growth factors from PRP, PRF, and advanced-PRF. Clin Oral Investig 2016;20:2353-2360.

31 Weibrich G, Hansen T, Kleis W, Buch R, Hitzler WE: Effect of platelet concentration in platelet-rich plasma on peri-implant bone regeneration. Bone 2004;34: 665-671.

32 Cheung LK, Chow Lk, Tsang MH, Tung LK: An evaluation of complications following dental extractions using either sterile or clean gloves. Int J Oral Maxillofac Surg 2001;30:550-554.

33 Landry R, Turnbull R, Howley T: Effectiveness of benzydamine $\mathrm{HCl}$ in the treatment of periodontal postsurgical patients. Res Clin Forums 1998;10:105-118.

34 Lindh C, Horner K, Jonasson G, Olsson P, Rohlin M, Jacobs R, Karayianni K, van der Stelt P, Adams J, Marjanovic E, Pavitt S, Devlin H: The use of visual assessment of dental radiographs for identifying women at risk of having osteoporosis: the OSTEODENT project. Oral Surg Oral Med Oral Pathol Oral Radiol Endod 2008;106:285-293.

35 Masse JF, Landry RG, Rochette C, Dufour L, Morency R, D'aoust P: Effectiveness of soft laser treatment in periodontal surgery. Int Dent J 1993;43:121-127.

36 Melzack R: The McGill pain questionnaire: from description to measurement. Anesthesiology 2005;103: 199-202. 